\title{
CRESCIMENTO DE CAPINS TROPICAIS CULTIVADOS EM CONSÓRCIO COM MILHO NO PLANALTO CATARINENSE
}

\author{
EDUARDO LEONEL BOTTEGA ${ }^{1}$, KELEN CRISTINA BASSO ${ }^{2}$, \\ JONATAS THIAGO PIVA², SAMUEL LUIZ FIOREZE ${ }^{2}$, RENATA FRANCIÉLI MORAES ${ }^{3}$ \\ e LAERCIO FRANCISCO FERRARI ${ }^{2}$
}

${ }^{1}$ Universidade Federal de Santa Maria (UFSM), campus de Cachoeira do Sul/RS, bottega.elb@gmail.com ${ }^{2}$ Universidade Federal de Santa Catarina (UFSC), campus de Curitibanos/SC, kelen.basso@ufsc.br, jonatas.piva@ufsc.br,s.fioreze@ufsc.br,laercio.ferrari@hotmail.com ${ }^{3}$ Universidade Federal do Paraná (UFPR),Curitiba/PR, renatafrmoraes@gmail.com

Revista Brasileira de Milho e Sorgo, v.15, n.3, p. 509-519, 2016

\begin{abstract}
RESUMO - O consórcio de milho com capins trata-se de uma prática bastante utilizada em regiões de clima tropical; entretanto, nada se conhece sobre sua adoção em regiões de clima temperado. Este trabalho objetivou avaliar o crescimento de diferentes capins e sua influência sobre o rendimento do milho em função do sistema de semeadura adotado no cultivo em consórcio no Planalto Catarinense. O experimento foi implantado em esquema fatorial 3x3, sendo os fatores compostos por três sistemas de semeadura do capim e três cultivares de braquiária. As médias foram avaliadas pelo teste de Tukey, a 5\% de probabilidade. O maior aporte de matéria seca total foi obtido pelo capim Urochloa ruziziensis cv. Ruziziensis. As espécies de capim estudadas apresentaram boa adaptação para o consórcio com a cultura do milho no Planalto Catarinense, sem afetar a produtividade da cultura do milho.
\end{abstract}

Palavras-chave: Urochloa brizantha, U. ruziziensis, Zea mays, Produtividade, Integração Lavoura-Pecuária.

\section{GROWTH OF TROPICAL GRASSES CULTIVATED WITH MAIZE IN THE SANTA CATARINA STATE}

\begin{abstract}
The intercropping maize with grasses is a practice widely used in tropical climates, but nothing is known about the use in temperate regions. This study aimed to evaluate the growth of different grasses and the effect on maize yield considering the seeding system adopted in the intercropping. The experiment was established in a $3 \times 3$ factorial scheme comprising three grass seeding systems and three cultivars of grass. The means were evaluated by Tukey test at $5 \%$ probability. The higher amount of total dry matter was observed in Urochloa ruziziensis cv. Ruziziensis. The studied grass species showed good adaptation to the intercropping with maize in Santa Catarina Plateau, without affecting the maize yield.
\end{abstract}

Keywords: Urochloa brizantha, U. ruziziensis, Zea mays, Yield, Crop Livestock Integration. 
O Planalto Catarinense trata-se de uma região do estado de Santa Catarina que apresenta seus campos produtivos localizados em altitudes que podem variar de 900 a $1.350 \mathrm{~m}$ acima do nível do mar. O clima predominante na região é classificado como temperado (mesotérmico úmido e verão ameno), segundo classificação de Köeppen. A precipitação média anual varia de 1.500 a $1.700 \mathrm{~mm}$, com temperatura média anual de $17^{\circ} \mathrm{C}$. Este clima favorece a formação de pastagens de inverno; entretanto, é observado um vazio forrageiro no período do verão. Neste contexto, o estudo do cultivo de capins forrageiros em consórcio com culturas de grãos cultivadas no verão mostra-se promissor, em especial aquele realizado no sistema de plantio direto.

O plantio direto trata-se de um sistema de produção conservacionista capaz de garantir sustentabilidade de atividades agropecuárias; entretanto, os ganhos podem ser limitados pela falta de rotação de culturas. A utilização de pastagens em áreas de lavoura, por períodos de dois anos ou mais, pode contribuir para a melhoria da qualidade física dos solos (Machado \& Assis, 2010). Neste contexto, o cultivo consorciado de culturas, em especial de milho com capins, tem se destacado, principalmente nas regiões tropicais, em função das condições climáticas ideais ao crescimento e ao desenvolvimento dos capins. Capins do gênero Urochloa apresentam significativo acúmulo de fitomassa a partir dos 45 dias após a semeadura, que, associado ao hábito perene (Pacheco et al., 2008), torna a espécie uma alternativa viável para a produção de forragem para pastagem ou cobertura do solo.

Borghi et al. (2008) enfatizam que o sistema de consórcio, em especial o de milho com capins, além de fornecer forragem após a colheita da cultura produtora de grãos, é uma excelente alternativa na for- mação de palha sobre o solo para semeadura da próxima safra de verão no sistema plantio direto. Estudos conduzidos por Machado e Assis (2010) avaliaram as produções de palha e de forragem por forrageiras anuais e perenes implantadas em sucessão à cultura da soja e observaram que as espécies Urochloa ruziziensis e Urochloa decumbens, por manterem-se em crescimento durante toda a estação seca e pela facilidade de dessecação, são boas alternativas quando se busca cobertura do solo em sistemas produtivos conservacionistas.

A adoção do sistema conservacionista envolve mudanças que podem reduzir temporariamente a produtividade das culturas (Gomez-Rey et al., 2014), o que, em um primeiro momento, pode restringir seu emprego. Contudo, Thierfelder e Wall (2009) destacam como benefícios deste sistema melhorias na parte física do solo, tais como o aumento na infiltração de água, as reduções do escoamento superficial e da evaporação, o aumento na disponibilidade de água no solo e a redução dos efeitos da seca em situações de baixa pluviosidade. Neste contexto, o cultivo de forrageiras como plantas de cobertura merece destaque, pois, além dos benefícios acima citados, elas proporcionam melhorias no que diz respeito à parte química do solo (ciclagem de nutrientes) e também nas variáveis de ordem sanitária (Machado \& Assis, 2010), como por exemplo supressão de plantas daninhas.

A utilização do cultivo consorciado de milho e capim é consagrada em regiões tropicais do país. Entretanto, pouco se sabe sobre a adoção do emprego de capins tropicais em consórcio com milho em regiões de clima temperado, como no caso dos campos localizados no Planalto Catarinense. Nessas regiões, a ocorrência de temperaturas elevadas e a maior duração do período diário de irradiação solar são observadas nos decorreres da primavera e do verão, fatores 
determinantes para o desenvolvimento de espécies tropicais. Diante do exposto, os objetivos deste trabalho foram avaliar o crescimento e o desenvolvimento de diferentes capins em função do sistema de semeadura adotado no cultivo em consórcio com milho e também sua influência sobre os componentes de rendimento da cultura do milho no Planalto Catarinense.

\section{Material e Métodos}

O experimento foi conduzido na Fazenda Agropecuária da Universidade Federal de Santa Catarina, no município de Curitibanos, SC, com coordenadas geográficas $27^{\circ} 16^{\prime} 34^{\prime \prime}$ de latitude Sul e $50^{\circ} 30^{\prime} 12^{\prime \prime}$ de longitude Oeste. A área apresenta altitude média em relação ao nível do mar de $1.000 \mathrm{~m}$. O clima da região é classificado como temperado (mesotérmico úmido e verão ameno), segundo classificação de Köeppen. A precipitação média anual varia de $1.500 \mathrm{a}$ $1.700 \mathrm{~mm}$, com temperatura média anual de $17^{\circ} \mathrm{C}$. O solo da área experimental é classificado como Cambissolo Háplico de textura argilosa, apresentando em média $550 \mathrm{~g} \mathrm{~kg}^{-1}$ de argila (Santos et al., 2006).

$\mathrm{O}$ experimento foi implantado em delineamento em blocos casualizados em esquema fatorial $3 \times 3$ com três repetições. Os fatores foram compostos por três sistemas de semeadura do capim (na linha, na entrelinha e a lanço) e três tipos de capim (U. brizantha cv. Xaraés; U. brizantha cv. Marandu e U. ruziziensis cv. Ruziziensis), as sementes foram semeadas a uma profundidade média de 0,03 $\mathrm{m}$. A combinação dos sistemas de semeadura com os capins resultou em nove tratamentos. Cada parcela experimental apresentou área de $18 \mathrm{~m}^{2}$, sendo $4,5 \mathrm{~m}$ de comprimento por $4 \mathrm{~m}$ de largura, composta por cinco linhas de cultivo de milho espaçadas em $0,80 \mathrm{~m}$. A área útil, utilizada nas avaliações dos componentes de rendimento do milho, foi de $9,6 \mathrm{~m}^{2}$, composta das três linhas centrais, descartando-se duas linhas da bordadura e $0,5 \mathrm{~m}$ da extremidade de cada linha. Nas avaliações dos capins na linha e na entrelinha, foram utilizadas as três linhas centrais da parcela, totalizando uma área útil de 9,6 $\mathrm{m}^{2}$; na semeadura a lanço, também foi desconsiderada a área de bordadura, totalizando $12 \mathrm{~m}^{2}$.

Antes da semeadura, foram coletadas amostras de solo representativas da profundidade 0,00-0,20 m para caracterização da fertilidade da área. As amostras foram encaminhadas para análise e os resultados serviram como base para recomendação de adubação. Na Tabela 1, são apresentados os valores resultantes da análise de solo.

Na semeadura do milho, foi utilizada uma semeadora-adubadora de precisão, marca Vence Tudo ${ }^{\circledR}$, modelo SA 11500. Para adubação de base, foram utilizados $420 \mathrm{~kg} \mathrm{ha}^{-1}$ do adubo formulado NPK (00-20-20). Tanto a semeadura do milho quanto a dos capins foi realizada no dia 10 de dezembro de 2013 , sendo que os capins foram semeados manualmente a uma profundidade de $0,03 \mathrm{~m}$.

Foi utilizado o híbrido de milho AG122, depositando seis sementes por metro a uma profundidade de 0,05 m. No estádio V4 de desenvolvimento das plantas, foi realizada adubação de cobertura aplicando-se $150 \mathrm{~kg} \mathrm{ha}^{-1}$ de ureia $(45 \%$ de $\mathrm{N})$ a lanço. A quantidade de sementes de capim semeada por hectare foi determinada com base no valor cultural de cada espécie. Foram utilizados $9 \mathrm{~kg} \mathrm{ha}^{-1}$ de sementes de $U$. ruziziensis cv. Ruziziensis, $9 \mathrm{~kg} \mathrm{ha}^{-1}$ de sementes de $U$. brizantha cv. Marandu e $8 \mathrm{~kg} \mathrm{ha}^{-1}$ de sementes de $U$. brizantha cv. Xaraés, visando a uma população de dez a 12 plantas por $\mathrm{m}^{2}$.

A colheita do milho foi realizada de forma manual 148 dias após a semeadura, sendo recolhidas todas as espigas presentes na área útil da parcela. Para 
a avaliação dos componentes de rendimento, foram selecionadas dez espigas escolhidas de forma aleatória em cada parcela experimental. Os componentes de rendimento avaliados foram: comprimento da espiga, diâmetro da espiga, número de fileiras por espiga, número de grãos por fileira e peso de 1.000 grãos. A produtividade foi determinada através da pesagem de grãos colhidos na parcela útil, ajustando-se para $14 \%$ de umidade.

Imediatamente após a colheita do milho, foram coletadas duas amostras de forragem por parcela, utilizando-se uma moldura de $0,25 \mathrm{~m}^{2}$, e todos os perfilhos foram cortados ao nível do solo, acondicionados em sacos plásticos e levados ao laboratório para pesagem. Uma subamostra foi utilizada para separação dos componentes morfológicos (folha, colmo e material morto) e outra subamostra utilizada para determinação da massa de matéria seca (MS). As amostras foram levadas a estufa a $65^{\circ} \mathrm{C}$ até massa constante. Os valores de massa de forragem foram convertidos para $\mathrm{kg} \mathrm{ha}^{-1}$ de MS e os componentes da forragem em porcentagem da massa de forragem. A relação fo- lha:colmo foi obtida pela divisão dos valores médios absolutos de folhas pelos valores médios absolutos de colmos em cada parcela. Além das avaliações relacionadas a produção de massa de forragem do capim, estimou-se a densidade de perfilhos, utilizando-se um retângulo de $0,50 \times 0,25 \mathrm{~m}$, sendo contados todos os perfilhos contidos dentro do retângulo; posteriormente, extrapolaram-se os valores para $\mathrm{m}^{2}$.

A análise de variância dos dados foi realizada através do teste de F de Snedcor, a 5\% de probabilidade. Constatando-se variância significativa, procedeu-se ao teste de Tukey, a 5\% de probabilidade, para comparação de médias. A análise de variância e o teste de médias foram realizados utilizando o programa estatístico ASSISTAT (Silva \& Azevedo, 2002).

\section{Resultados e Discussão}

Na Tabela 2, é apresentado o resumo da análise de variância dos parâmetros estudados. O tipo de semeadura dos capins (linha, entrelinha, lanço) influenciou de forma significativa a massa de matéria

Tabela 1. Características químicas do solo na camada de $0-20 \mathrm{~cm}$ na área experimental antes da implantação do experimento. Curitibanos, SC, 2013.

\begin{tabular}{|c|c|c|c|c|c|c|}
\hline $\begin{array}{c}\mathrm{MO} \\
\mathrm{g} \mathrm{dm}^{-3}\end{array}$ & $\begin{array}{c}\mathrm{pH} \\
\mathrm{CaCl}_{2}\end{array}$ & P & K & $\mathrm{Ca}$ & $\begin{array}{c}\text { CTC } \\
-3\end{array}$ & $\begin{array}{c}\mathrm{V} \\
(\%)\end{array}$ \\
\hline 52,27 & 4,90 & 2,62 & 50,83 & 5,92 & 13,52 & 68,93 \\
\hline
\end{tabular}

Tabela 2. Resumo da análise de variância para massa de matéria seca total (MST), massa de matéria seca de folhas (MSF), massa de matéria seca de colmos (MSC) e massa de matéria seca de material morto (MSMM) de capins semeados na linha, na entrelinha e a lanço em consórcio com o milho. Curitibanos, SC, 2014.

\begin{tabular}{ccccc}
\hline \multirow{2}{*}{$\mathrm{FV}^{1}$} & \multicolumn{4}{c}{ Teste F de Snedcor } \\
\cline { 2 - 5 } & MST & MSF & MSC & MSMM \\
\hline Semeadura (S) & $4,84^{*}$ & $6,53^{* *}$ & $2,27^{\text {ns }}$ & $0,38^{\text {ns }}$ \\
Capins (C) & $87,62^{* *}$ & $23,92^{* *}$ & $110,68^{* *}$ & $13,39^{* *}$ \\
S x C & $0,97^{\text {ns }}$ & $1,43^{\text {ns }}$ & $0,46^{\text {ns }}$ & $0,67^{\text {ns }}$ \\
\hline
\end{tabular}

${ }^{1}$ Fator de variação. **significativo ao nível de $1 \%$ de probabilidade. * significativo ao nível de $5 \%$ de probabilidade. ${ }^{\text {ns }}$ não significativo. 
seca total (MST) e a massa de matéria seca de folhas (MSF). Todos os parâmetros avaliados apresentaram diferença significativa em função do tipo de capim cultivado (U. ruziziensis cv. Ruziziensis, U. brizantha cv. Marandu e U. brizantha cv. Xaraés). Não foi observada interação significativa entre os tipos de semeadura de capim adotada e o tipo de capim cultivado.

A maior produção média total de massa seca de forragem, independente do arranjo de semeadura, foi obtida pelo capim Ruziziensis (6.892 $\left.\mathrm{kg} \mathrm{ha}^{-1}\right)$, conforme apresentado na Tabela 3. Quando a semeadura foi realizada na linha, independente do capim, obteve-se menor produção média total de massa seca (4.054,31 $\left.\mathrm{kg} \mathrm{ha}{ }^{-1}\right)$. Não houve interação significativa entre o tipo de capim e o sistema de semeadura utilizado.

Pariz et al. (2011) avaliaram a produção de matéria seca dos capins Ruziziensis e Marandu, semeados a lanço e na linha em consórcio com o milho, e observaram maior produção de matéria seca do capim Ruziziensis quando semeado a lanço, diferindo em $1.800 \mathrm{~kg} \mathrm{ha}^{-1}$ em relação à semeadura na linha. A produção de massa do capim Marandu não apresentou diferença significativa em função do sistema de semeadura adotado.

Os capins Ruziziensis e Marandu apresentaram as maiores médias de produção de folhas $(2.252,50$ e $1.990,16 \mathrm{~kg} \mathrm{ha}^{-1}$, respectivamente) e de material morto (137,95 e 77,70 $\mathrm{kg} \mathrm{ha}^{-1}$, respectivamente), independente do tipo de semeadura empregada (Tabela 3). Freitas et al. (2005), Pariz et al. (2009) e Pariz et al. (2011) relatam que estes capins apresentam tolerância parcial ao sombreamento e à competição com a cultura acompanhante, não afetando de forma acentuada a produção.

A massa de colmos e material morto observada deve-se, principalmente, ao sombreamento dos estratos mais basais devido à interceptação lumino- sa exercida pelas plantas. Gramíneas em situação de sombreamento, na busca por luz, aumentam o alongamento de colmos como forma de expor as folhas mais novas na parte superior do dossel, onde existe maior incidência luminosa; porém, este mecanismo faz com que os estratos basais fiquem ainda mais sombreados, aumentando a senescência (Lemaire, 2001; Sbrissia \& Silva, 2008; Carnevalli et al., 2006). É provável, também, que o maior sombreamento na base das plantas tenha inibido o perfilhamento, haja visto que a redução na intensidade luminosa é um dos fatores de ambiente que reduz o perfilhamento em gramíneas (Deregibus et al., 1983).

Na semeadura a lanço, houve maior produção de folhas $\left(2.135,17 \mathrm{~kg} \mathrm{ha}^{-1}\right)$. Neste tipo de semeadura, ocorre melhor distribuição (arranjo) das plantas na área, mesmo estando na mesma densidade de plantas (Pariz et al., 2011); tal fato permite a disposição de perfilhos mais ou menos próximos às plantas de milho, ou seja, em locais com maior ou menor interceptação luminosa. Nos locais onde ocorre maior radiação solar na base do dossel, a luz incidente ativa as gemas basais, mais perfilhos são formados e o perfilhamento é a principal característica para o aumento na produção de folhas (Davies, 1974).

A maior produção de massa total de forragem do capim Ruziziensis pode estar associada à maior média de massa de colmos observada nesta cultivar (4.501,97 kg ha' ${ }^{-1}$; Tabela 2), sendo os colmos um componente que confere maior peso à massa total de forragem, porém com valores nutricionais muito abaixo do conteúdo das folhas. Além disso, não foi aplicada nenhuma subdosagem de herbicida nicosulfuron para retardar o crescimento das gramíneas.

As menores produções de forragem total, de folhas, de colmo e de material morto foram observadas para o capim Xaraés. Este fato pode ser explicado 
pela característica deste capim em apresentar germinação e crescimento mais lentos quando comparado com os outros capins estudados. Os resultados obtidos foram menores que os relatados em outros trabalhos que também avaliaram o consórcio de milho com a $U$. brizantha cv. Xaraés (Costa et al., 2012) realizados em regiões de clima tropical. É possível que o clima ameno, com noites mais frias, somado à competição das plantas em consórcio, tenha interferido no potencial de crescimento desta cultivar.

Costa et al. (2012) avaliaram a produtividade do milho em consórcio com os capins Xaraés e Ruzi- ziensis e doses de nitrogênio. Os resultados de massa de forragem total obtidos foram de 5.000 e $6.000 \mathrm{~kg}$ $\mathrm{ha}^{-1}$ de matéria seca, não sendo observada diferença entre as cultivares. Os autores ainda relatam que o consórcio garante forragem para o fornecimento à alimentação animal; após a colheita da cultura do milho, a pastagem estará estabelecida para utilização do outono à primavera.

Os resultados do teste de médias para número de perfilhos $\mathrm{m}^{-2}$, porcentagem de folhas $(\% \mathrm{~F})$, porcentagem de colmos $(\% \mathrm{C})$, porcentagem de material morto (\% MM) e relação folha colmo (RFC) dos di-

Tabela 3. Massa de matéria seca total (MST), massa de matéria seca de folhas (MSF), massa de matéria seca de colmos (MSC) e massa de matéria seca de material morto (MSMM) de capins semeados na linha, na entrelinha e a lanço em consórcio com o milho. Curitibanos, SC, 2014.

\begin{tabular}{|c|c|c|c|c|}
\hline \multirow{2}{*}{ Capim } & \multicolumn{4}{|c|}{$\operatorname{MST}\left(\mathrm{kg} \mathrm{ha}^{-1}\right)$} \\
\hline & Linha & Entrelinha & Lanço & Média \\
\hline Ruziziensis & $6.413,16$ & $6.286,00$ & $7.978,11$ & $6.892,42 \mathrm{~A}$ \\
\hline Marandu & $4.190,25$ & $5.327,13$ & $5.723,46$ & $5.080,28 \mathrm{~B}$ \\
\hline Xaraés & $1.550,52$ & $1.552,93$ & $2.046,68$ & $1.716,71 \mathrm{C}$ \\
\hline \multirow[t]{2}{*}{ Média } & $4.054,31 \mathrm{~b}$ & $4.388,69 \mathrm{ab}$ & $5.249,42 \mathrm{a}$ & $\mathrm{CV}^{1}(\%) 18,45$ \\
\hline & \multicolumn{4}{|c|}{$\operatorname{MSF}\left(\mathrm{kg} \mathrm{ha}^{-1}\right)$} \\
\hline Ruziziensis & $1.961,84$ & $1.864,68$ & $2.931,00$ & $2.252,50 \mathrm{~A}$ \\
\hline Marandu & $1.512,62$ & $2.069,24$ & $2.388,63$ & $1.990,16 \mathrm{~A}$ \\
\hline Xaraés & 863,55 & 904,96 & $1.085,91$ & $951,47 \mathrm{~B}$ \\
\hline \multirow[t]{2}{*}{ Média } & $1.446,00 \mathrm{~b}$ & $1.612,96 \mathrm{~b}$ & $2.135,17 \mathrm{a}$ & $\mathrm{CV}(\%) 24,38$ \\
\hline & \multicolumn{4}{|c|}{ MSC $\left(\mathrm{kg} \mathrm{ha}^{-1}\right)$} \\
\hline Ruziziensis & $4.281,18$ & $4.274,83$ & $4.949,91$ & $4.501,97 \mathrm{~A}$ \\
\hline Marandu & $2.604,18$ & $3.189,68$ & $3.243,37$ & $3.012,41 \mathrm{~B}$ \\
\hline Xaraés & 677,90 & 630,63 & 960,77 & $756,43 \mathrm{C}$ \\
\hline \multirow[t]{2}{*}{ Média } & $2.521,09$ & $2.698,38$ & $3.051,35$ & $\mathrm{CV}(\%) 19,51$ \\
\hline & \multicolumn{4}{|c|}{$\operatorname{MSMM}\left(\mathrm{kg} \mathrm{ha}^{-1}\right)$} \\
\hline Ruziziensis & 170,15 & 146,49 & 97,21 & $137,95 \mathrm{~A}$ \\
\hline Marandu & 73,45 & 68,20 & 91,46 & $77,70 \mathrm{~A}$ \\
\hline Xaraés & 9,07 & 17,34 & 0,00 & $8,80 \mathrm{~B}$ \\
\hline Média & 84,22 & 77,34 & 62,89 & $\mathrm{CV}(\%) 70,81$ \\
\hline
\end{tabular}

Médias seguidas pela mesma letra, maiúscula na coluna e minúscula na linha, não diferem estatisticamente entre si pelo Teste de Tukey $(\mathrm{p}<0,05) .{ }^{1}$ Coeficiente de variação. 
ferentes capins semeados na linha, na entrelinha e a lanço em consórcio com o milho são apresentados na Tabela 4.

Os capins Ruziziensis e Marandu apresentaram o maior perfilhamento (237,6 e 197,9 perfilhos $\mathrm{m}^{-2}$, respectivamente), sendo esses também os capins que foram mais produtivos. A semeadura a lanço foi a que proporcionou maior perfilhamento, sendo contabilizados, em média, 208,7 perfilhos $\mathrm{m}^{-2}$ (Tabela 4). A densidade populacional de perfilhos é uma característica importante, pois a produção de matéria seca de uma pastagem é diretamente relacionada ao número de perfilhos. Na semeadura a lanço, pode ter ocorrido maior distribuição das plantas na área, o que permitiu

Tabela 4. Número de perfilhos $\left(\mathrm{m}^{2}\right)$, porcentagem de folhas $(\% \mathrm{~F})$, porcentagem de colmos $(\% \mathrm{C})$, porcentagem de material morto (\% MM) e relação folha colmo (RFC) de diferentes capins semeados na linha, na entrelinha e a lanço em consórcio com o milho. Curitibanos, SC, 2014.

\begin{tabular}{|c|c|c|c|c|}
\hline \multirow{2}{*}{ Capim } & \multicolumn{4}{|c|}{ PERFILHOS } \\
\hline & Linha & Entrelinha & Lanço & Média \\
\hline Ruziziensis & 228,7 & 189,0 & 295,0 & $237,6 \mathrm{~A}$ \\
\hline Marandu & 148,7 & 192,0 & 253,0 & $197,9 \mathrm{~A}$ \\
\hline Xaraés & 60,0 & 57,0 & 78,0 & $65,0 \mathrm{~B}$ \\
\hline Média & $145,8 \mathrm{~b}$ & $146,0 \mathrm{~b}$ & $208,7 \mathrm{a}$ & $\mathrm{CV}^{1}(\%) 21,87$ \\
\hline \multirow{2}{*}{ Capim } & \multicolumn{4}{|c|}{$\% \mathrm{~F}$} \\
\hline & Linha & Entrelinha & Lanço & Média \\
\hline Ruziziensis & 30,37 & 29,65 & 37,00 & $32,34 \mathrm{C}$ \\
\hline Marandu & 37,21 & 38,93 & 40,64 & 38,93 B \\
\hline Xaraés & 55,16 & 57,72 & 53,83 & $55,57 \mathrm{~A}$ \\
\hline \multirow[t]{2}{*}{ Média } & 40,91 & 42,10 & 43,82 & $\mathrm{CV}(\%) 9,29$ \\
\hline & \multicolumn{4}{|c|}{$\% \mathrm{C}$} \\
\hline Ruziziensis & 66,69 & 68,02 & 61,77 & 65,49 A \\
\hline Marandu & 61,13 & 59,81 & 57,81 & $59,54 \mathrm{~B}$ \\
\hline Xaraés & 44,06 & 41,48 & 46,17 & $43,91 \mathrm{C}$ \\
\hline \multirow[t]{2}{*}{ Média } & 57,30 & 56,44 & 55,21 & $\mathrm{CV}(\%) 6,40$ \\
\hline & \multicolumn{4}{|c|}{$\% \mathrm{MM}$} \\
\hline Ruziziensis & 2,94 & 2,31 & 1,23 & $2,19 \mathrm{~A}$ \\
\hline Marandu & 1,64 & 1,26 & 1,66 & $1,52 \mathrm{AB}$ \\
\hline Xaraés & 0,74 & 0,80 & 0,00 & $0,52 \mathrm{C}$ \\
\hline \multirow[t]{2}{*}{ Média } & 1,77 & 1,46 & 0,96 & $\mathrm{CV}(\%) 79,36$ \\
\hline & \multicolumn{4}{|c|}{ RFC } \\
\hline Ruziziensis & 0,46 & 0,43 & 0,60 & $0,50 \mathrm{C}$ \\
\hline Marandu & 0,62 & 0,65 & 0,72 & $0,67 \mathrm{~B}$ \\
\hline Xaraés & 1,20 & 1,40 & 1,17 & $1,27 \mathrm{~A}$ \\
\hline Média & 0,77 & 0,82 & 0,83 & $\mathrm{CV}(\%) 14,66$ \\
\hline
\end{tabular}

Médias seguidas pela mesma letra, maiúscula na coluna e minúscula na linha, não diferem estatisticamente entre si pelo Teste de Tukey $(\mathrm{p}<0,05) .{ }^{1}$ Coeficiente de variação. 
que maior quantidade de luz chegasse à base do dossel, o que pode aumentar o perfilhamento devido à ativação das gemas basais.

A porcentagem de folhas foi maior no capim Xaraés $(55,57 \%)$ e não variou com os arranjos de semeadura (Tabela 4). Esta é uma variável importante quando se almeja o retorno mais rápido de matéria orgânica para o solo devido à menor relação $\mathrm{C}: \mathrm{N}$ que a fração colmos, como também para a formação do pasto devido à maior capacidade fotossintética e ao valor nutritivo. O capim Xaraés também apresentou a maior relação folha:colmo $(1,27)$. Apesar de ter sido observada menor massa de forragem total, a maior parte desta foi composta por folhas, característica desejável quando o objetivo é a formação de pastagem.

Menores valores de \% F $(32,24 \%)$ e RFC $(0,50)$ foram observados no capim Ruziziensis e maior $\% \mathrm{C}$ $(65,49 \%)$. Esta cultivar possui colmos geniculados e seu hábito de crescimento é mais prostrado e, segundo Costa et al. (2012), ocupa rapidamente o solo. Sereia et al. (2012) avaliaram os capins Ruziziensis e Marandu e observaram que os maiores índices de colmos e de produtividade de massa também foram observados no capim Ruziziensis.

O capim Marandu apresentou valores de produção de massa de forragem, de folhas e de colmos intermediários, porém com massa seca de folhas semelhante ao capim Ruziziensis, sem, no entanto, apresentar igual porcentagem de colmos. Dias Filho (2002) relata que a $U$. brizantha sombreada reduz sua capacidade fotossintética, porém apresenta determinada plasticidade fenotípica e tolerância em resposta ao sombreamento, o que permite o crescimento e a viabilidade do consórcio.

Os componentes da produção e a produtividade do milho não foram afetados pelo consórcio com os capins testados. (Tabela 5). De acordo com a Conab (2014), a produtividade média de milho obtida na maioria dos tratamentos foi próxima à média estadual (7.334 $\left.\mathrm{kg} \mathrm{ha}^{-1}\right)$ e superior à média nacional (4.755 $\left.\mathrm{kg} \mathrm{ha}^{-1}\right)$. Estes resultados indicam que o cultivo em consórcio de milho com capins tropicais mostra-se promissor, uma vez que, além da produção de grãos, o agricultor pode contar com o aporte de forragem no período em que esta é escassa na região. Goetten (2014), estudando o efeito da adubação nitrogenada na cultura do milho em experimento conduzido nos mesmos talhão e época em que o presente estudo foi realizado, constatou produtividade de $3.000 \mathrm{~kg} \mathrm{ha}^{-1}$ para testemunha $(0 \mathrm{~kg}$ de $\mathrm{N})$, valor este inferior à menor produtividade obtida neste estudo $(6.101,39$ $\mathrm{kg} \mathrm{ha}^{-1}$ ), mais uma vez demostrando o potencial do cultivo consorciado entre milho e capins tropicais no Planalto Catarinense.

O peso de 1.000 grãos também não diferiu significativamente em estudo realizado por Richart et al. (2010) no estado do Paraná. O número de fileiras por espiga (NF) não foi influenciado pelos tratamentos estudados. De acordo com Freitas et al. (2013), o número de fileiras de grãos por espiga tem grande controle genético e, por isto, normalmente é pouco influenciado por fatores externos.

O comprimento de espiga (CE) e o diâmetro de espiga (DE) não apresentaram diferenças significativas, corroborando com resultados encontrados por Richart et al. (2010). Pariz et al. (2011) observaram em seu estudo que o capim Ruziziensis, quando semeado na linha e a lanço, apresentou variação no número de grãos por fileira. Segundo o autor, esta variação resulta em perda na produtividade. Resultado divergente foi observado no presente estudo, em que o sistema de semeadura do capim não influenciou significativamente o número de grãos por fileira.

De acordo com os resultados obtidos, o cultivo de milho em consórcio com os capins avaliados 
Tabela 5. Análise de variância para o comprimento de espiga (CE), o diâmetro de espiga (DE), o número de fileiras (NF), o número de grãos por fileira (NGF), o peso de 1.000 grãos (PMG) e a produtividade (PROD) de milho cultivado com três cultivares de capim (Ruziziensis, Marandu e Xaraés) em três sistemas de semeadura (na linha, na entrelinha e a lanço). Curitibanos, SC, 2014.

\begin{tabular}{ccccccc}
\hline Tratamentos $^{1}$ & CE $(\mathrm{cm})$ & DE $(\mathrm{cm})$ & NF & NGF & PMG $(\mathrm{kg})$ & ${\text { PROD }\left(\mathrm{kg} \mathrm{ha}^{-1}\right.}^{-12}$ \\
\hline RLI & 12,64 & 4,65 & 16,06 & 27,36 & 0,245 & $6.663,06$ \\
REL & 12,74 & 4,69 & 15,66 & 27,03 & 0,252 & $6.213,39$ \\
RLA & 12,53 & 4,55 & 15,60 & 27,40 & 0,234 & $6.101,39$ \\
MLI & 13,65 & 4,77 & 16,06 & 29,90 & 0,261 & $7.361,69$ \\
MEL & 13,50 & 4,71 & 16,13 & 30,26 & 0,245 & $6.843,16$ \\
MLA & 13,15 & 4,73 & 15,80 & 28,53 & 0,252 & $6.550,35$ \\
XLI & 13,28 & 4,76 & 16,20 & 29,86 & 0,258 & $7.204,13$ \\
XEL & 12,83 & 4,71 & 16,73 & 28,10 & 0,229 & $6.431,33$ \\
XLA & 13,88 & 4,86 & 16,26 & 30,73 & 0,265 & $7.571,53$ \\
\hline & & & Teste F de Snedcor & & $0,485^{\text {ns }}$ \\
\hline Semeaduras $(\mathrm{S})$ & $0,177^{\text {ns }}$ & $0,269^{\text {ns }}$ & $0,653^{\text {ns }}$ & $0,118^{\text {ns }}$ & $0,911^{\text {ns }}$ & $0,557^{\text {ns }}$ \\
Capins $(C)$ & $0,428^{\text {ns }}$ & $1,119^{\text {ns }}$ & $2,836^{\text {ns }}$ & $0,508^{\text {ns }}$ & $0,531^{\text {ns }}$ & $0,165^{\text {ns }}$ \\
S x C & $0,152^{\text {ns }}$ & $0,248^{\text {ns }}$ & $0,526^{\text {ns }}$ & $0,135^{\text {ns }}$ & $0,706^{\text {ns }}$ & 40,70 \\
\hline CV $^{2}(\%)$ & 23,56 & 6,32 & 3,50 & 24,44 & 16,35 & $0,44^{\text {ns }}$ \\
W & $0,629^{\text {ns }}$ & $0,575^{\text {ns }}$ & $0,058^{\text {ns }}$ & $0,372^{\text {ns }}$ & $0,762^{\text {ns }}$ & \\
\hline
\end{tabular}

${ }^{1}$ RLI: Urochloa ruziziensis cv. Ruziziensis semeada na linha de plantio do milho; REL: $U$. ruziziensis cv. Ruziziensis semeada na entrelinha de plantio do milho; RLA: U. ruziziensis cv. Ruziziensis semeada a lanço; MLI: U. brizantha cv. Marandu semeada na linha de plantio do milho; MEL: U. brizantha cv. Marandu semeada na entrelinha de plantio do milho; MLA: U. brizantha cv. Marandu semeada a lanço; XLI: U. brizantha cv. Xaraés semeada na linha de plantio do milho; XEL: U. brizantha cv. Xaraés semeada na entrelinha de plantio do milho; XLA: U. brizantha cv. Xaraés semeada a lanço. ns não significativo pelo Teste de Tukey (p $<0,05)$. W: Teste de normalidade de Shapiro-Wilks: ns distribuição normal $(\mathrm{p}<0,05) .{ }^{2}$ Coeficiente de variação.

mostrou-se alternativa viável, pois não influenciou de forma significativa a produtividade da cultura, fornecendo, após a colheita, um aporte forrageiro na época de maior déficit. Recomenda-se a repetição deste estudo em outros locais que apresentam clima temperado, buscando com isso um melhor entendimento da dinâmica do sistema de consórcio entre milho e capins tropicais.

\section{Conclusões}

O maior aporte de matéria seca total foi obtido pelo capim Urochloa ruziziensis cv. Ruziziensis.
As espécies de capim estudadas apresentaram boa adaptação para o consórcio com a cultura do milho no Planalto Catarinense.

\section{Referências}

BORGHI, E.; COSTA, N. V.; CRUSCIOL, C. A. C.; MATEUS, G. P. Influência da distribuição espacial do milho e da Brachiaria brizantha consorciados sobre a população de plantas daninhas em sistema plantio direto na palha. Planta Daninha, Rio de Janeiro, v. 26, p. 559-568, 2008.

DOI: $10.1590 / \mathrm{S} 0100-83582008000300011$. 
CARNEVALLI, R. A.; SILVA, S. C.; BUENO, A. A. O.; UEBELE, M. C.; BUENO, F. O.; SILVA, G. N.; MORAES, J. P. Herbage production and grazing losses in Panicum maximum cv. Mombaça under four grazing managements. Tropical Grasslands, Brisbane, v. 40, n. 3, p. 165-176, 2006.

CONAB. Companhia Nacional de Abastecimento. Acompanhamento da safra brasileira: grãos: oitavo levantamento. Brasília, DF, 2014. Disponível

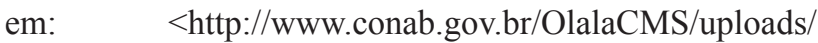
arquivos/14_05_08_10_11_00_boletim_graos_ maio_2014.pdf>. Acesso em: 5 ago. 2014.

COSTA，N. R.; ANDREOTTI, M.; GAMEIRO, R. A.; PARIZ, C. M.; BUZETTI, S.; LOPES, K. S. M. Adubação nitrogenada no consórcio de milho com duas espécies de braquiária em sistema plantio direto. Pesquisa Agropecuária Brasileira, Brasília, DF, v. 47, n. 8, p. 1038-1047, ago. 2012.

DOI: $10.1590 / \mathrm{S} 0100-204 \mathrm{X} 2012000800003$.

DAVIES, A. Leaf tissue remaining after cutting and regrowth in perennial ryegrass. Journal Agriculture Science, Cambridge, v. 82, p. 165-172, 1974.

DOI: $10.1017 / \mathrm{S} 0021859600050334$.

DEREGIBUS, V. A.; SANCHEZ, R. A.; CASAL, J. J. Effects of light quality on tiller production in Lolium spp. Plant Physiology, Bethesda, v. 72, n. 3, p. 900-912, 1983. DOI: $10.1104 /$ pp. 72.3 .900 .

DIAS FILHO, M. B. Photosynthetic light response of $\mathrm{C} 4$ grasses Brachiaria brizantha in Brachiaria humidicola under shade. Scientia Agricola, Piracicaba, v. 59, n. 1, p. 65-68, 2002.

DOI: $10.1590 / \mathrm{S} 0103-90162002000100009$.

FREITAS, F. C. L.; FERREIRA, L. R.; FERREIRA, F. A.; SANTOS, M. V.; AGNES, E. L.; CARDOSO, A. A.; JAKELAITIS, A. Formação de pastagem via consórcio de Brachiaria brizantha com o milho para silagem no sistema de plantio direto. Planta Daninha, Rio de Janeiro, v. 23, n. 1, p. 49-58, 2005.

DOI: $10.1590 / \mathrm{S} 0100-83582005000100007$.
FREITAS, R. J.; NASCENTE, A. S.; SANTOS, F. L. S. População de plantas de milho consorciado com Urochloa ruziziensis. Pesquisa Agropecuária Tropical, Goiânia, v. 43, n. 1, p. 79-87, 2013

DOI: $10.1590 / \mathrm{S} 1983-40632013000100011$.

GOETTEN, M. Adubação nitrogenada no milho em sistema de integração lavoura-pecuária. 2014. 24 f. Monografia (Graduação em Agronomia) - Universidade Federal de Santa Catarina, Curitibanos, 2014.

GOMEZ-REY, M. X.; GARCIA-MARCO, S.; GONZALEZ-PRIETO, S. J. Soil P and cation availability and crop uptake in a forage rotation under conventional and reduced tillage. Soil Use and Management, Oxford, v. 30, n. 4, p. 1-9, 2014.

DOI: $10.1111 /$ sum.12156.

LEMAIRE, G. Ecophisiology of grasslands: dynamic aspects of forage plant populations in grazed swards. In: INTERNATIONAL GRASSLAND CONGRESS, 19., 2001, São Pedro. Grassland ecosystems: an outlook into the 21st century: proceedings. Brasília, DF: Sociedade Brasileira deZootecnia; Piracicaba:FEALQ, 2001.p.29-37.

MACHADO, L. A. Z.; ASSIS, P. G. A. Produção de palha e forragem em sucessão à soja. Pesquisa Agropecuária Brasileira, Brasília, DF, v. 45, n. 4, p. 415-422, 2010. DOI: 10.1590/S0100-204X2010000400010.

PACHECO, L. P.; PIRES, F. R.; MONTEIRO, F. P.; PROCÓPIO, S. de O.; ASSIS, R. L. de; CARMO, M. L. do; PETTER, F. A. Desempenho de plantas de cobertura em sobressemeadura na cultura da soja. Pesquisa Agropecuária Brasileira, Brasília, DF, v. 43, n. 7, p. 815823, jul. 2008.

DOI: $10.1590 / \mathrm{S} 0100-204 X 2008000700005$.

PARIZ, C. M.; ANDREOTTI, M.; TARSITANO, M. A. A.; BERGAMASCHINE, A. F.; BUZETTI, S.; CHIODEROLI, C.A. Desempenhos técnicos e econômicos da consorciação de milho com forrageiras dos gêneros Panicum e Brachiaria em sistema de integração lavourapecuária. Pesquisa Agropecuária Tropical, Goiânia, v. 39, n. 4, p. 360-370, 2009. 
PARIZ, C. M.; ANDREOTTI, M.; AZENHA, M. V.; BERGAMASCHINE, A. F.; MELLO, L. M. M.; LIMA, R. C. Produtividade de grãos de milho e massa seca de braquiárias em consórcio no sistema de integração lavourapecuária. Ciência Rural, Santa Maria, v. 41, n. 5, p. 875882, maio 2011.

DOI: $10.1590 / \mathrm{S} 0103-84782011000500023$.

RICHART, A.; PASLAUSKI, T.; NOZAKI, M. H.; RODRIGUES, C. M.; FEY, R. Desempenho do milho safrinha e da Brachiaria ruziziensis cv. comum em consórcio. Revista Brasileira de Ciências Agrárias, Recife, v. 5, n. 4, p. 497-502, 2010.

DOI: 10.5039/agraria.v5i4a855.

SANTOS, H. G. dos; JACOMINE, P. K. T.; ANJOS, L. H. C. dos; OLIVEIRA, V. A. de; OLIVEIRA, J. B. de; COELHO, M. R.; LUMBRERAS, J. F.; CUNHA, T. J. F. (Ed.). Sistema brasileiro de classificação de solos. 2. ed. Rio de Janeiro: Embrapa Solos, 2006. 306 p.

SBRISSIA, A. F.; SILVA, S. C. Compensação tamanho/ densidade populacional de perfilhos em pastos de capim- marandu. Revista Brasileira de Zootecnia, Viçosa, MG, v. 37, n. 1, p. 35-47, 2008.

DOI: $10.1590 / \mathrm{S} 1516-35982008000100005$.

SEREIA, R. C.; LEITE, L. F.; ALVES, V. B.; CECCON, G. Crescimento de Brachiaria spp. e milho safrinha em cultivo consorciado. Revista Agrarian, Dourados, v. 5, n. 18, p. 349-355, 2012.

SILVA, F. A. S. E.; AZEVEDO, C. A. V. Versão do programa computacional Assistat para o sistema operacional Windows. Revista Brasileira de Produtos Agroindustriais, Campina Grande, v. 4, n. 1, p. 71-78, 2002.

THIERFELDER, C.; WALL, P. C. Effects of conservation agriculture techniques on infiltration and soil water content in Zambia and Zimbabwe. Soil and Tillage Research, Amsterdam, v. 105, n. 2, p. 217-227, 2009.

DOI: $10.1016 /$ j.still.2009.07.007. 